\title{
Evolution of Glycemic Targets in Management of Diabetes
}

\author{
Muhammad Qamar Masood \\ Department of Medicine, Aga Khan University, Stadium Road, Karachi, Pakistan \\ Email: qamar.masood@aku.edu
}

How to cite this paper: Masood, M.Q. (2021) Evolution of Glycemic Targets in Management of Diabetes. Journal of Diabetes Mellitus, 11, 208-220. https://doi.org/10.4236/jdm.2021.115018

Received: September 28, 2021

Accepted: November 13, 2021

Published: November 16, 2021

Copyright (c) 2021 by author(s) and Scientific Research Publishing Inc. This work is licensed under the Creative Commons Attribution International License (CC BY 4.0).

http://creativecommons.org/licenses/by/4.0/ (c) (i) Open Access

\begin{abstract}
How goals of diabetes management evolved over the last hundred years was largely dependent on the understanding of association of hyperglycemia with chronic complications, development of safe and effective therapeutic options and monitoring capabilities. Insulin ended the era of death in type 1 diabetes (T1D) but an era of chronic complications emerged. The medical community and policy makers were not convinced that near normal glycemia would prevent these complications. Diabetes Control and Complication Trial (DCCT) has a huge impact on how diabetes is managed today, hemoglobin A1C (A1C) of less than 7\% emerged as a main therapeutic objective. However DCCT and later United Kingdom Prospective Diabetes Study (UKPDS) in type 2 diabetes (T2D), failed to show a safe lower cutoff where microvascular complications could be maximally reduced without additional risk of hypoglycemia. Moreover macrovascular complications could not be adequately addressed in these study populations. An over enthusiastic approach in the Action to Control Cardiovascular Risk in Type 2 Diabetes (ACCORD) trial resulted in an increase in overall and cardiovascular mortality, this led to concept of individualization of glycemic targets and "lower the better" is not appropriate for everyone. At the same time the follow up epidemiological data of DCCT and UKPDS reveal that good glycemic control earlier has long term benefits, the concept of legacy effect and led to the idea of "earlier the better". Later advances in therapeutic options and monitoring capabilities have made it possible to safely achieve intensive glycemic goals, however widespread availability and cost precludes its common use.
\end{abstract}

\section{Keywords}

Glycemic Targets, HbA1c, Chronic Complications, DCCT 


\section{Introduction}

The goals of glycemic control have evolved and matured over the years with periods of denial to over enthusiastic approaches and finally an individualized and patient centered approach. Over the years it was learnt that one size does not fit all and due consideration to patient characteristics, benefits and harms of pharmacotherapy, patients' preferences, and treatment burden and cost is important. How goals of diabetes management evolved over the last hundred years can be studied in different eras as evidence emerged and changed the practices and recommendations in these periods.

\section{Pre Insulin Era}

Until the advent of insulin prolonging survival and minimizing glycosuria were the mainstay of treatment goal. Dr. Frederick Allen's proposed starvation therapy became the standard of care, this was a desperate attempt to keep diabetics alive at the expense of inanition and death due to starvation. His book Total Dietary Regulation in the Treatment of Diabetes, published in 1919, contained extensive records of 76 of his patients treated with dietary therapy. This nevertheless allowed hundreds of diabetic patients to be kept alive long enough to benefit from the newly available insulin therapy [1].

\section{Discovery of Insulin to DCCT}

With the advent of insulin launched a new era of diabetes management. Elliot P. Joslin noted, however, that "the disease ... was far from solved by insulin. Insulin marked the end of one era in diabetes management, not the end of diabetes".

Disappearance of sugar and ketones in urine and gaining back of weight and physical strength were the initial goals of management in patients who were the first ones to receive the insulin [2] [3]. Dr. Joslin was the proponent of the notion that good glucose control would prevent complications. This remains debated for decades by other endocrinologists and scientists, until 1993 when DCCT validated his opinion [3].

Goals of glucose control cannot be established until you have means of measuring it. The first hospital blood glucose monitoring system for pre-meal testing was developed under Dr. Joslin's direction in 1940 [4].

Benedict solution for testing urine sugar made available in 1908 and used for more than 50 years, urine strips were made available for home testing in 1960s. In 1965, Ames developed the first blood glucose test strip, the Dextrostix, using glucose oxidase, the color generated was then compared to a chart on the bottle, the Dextrometer was launched in 1980; this meter used the Dextrostix along with a digital display. During the 1980s, self-monitoring of blood glucose (SMBG) became the standard of care, especially for patients with type 1 diabetes [5]. This advance, along with A1C testing and insulin pump therapy, made possible the Diabetes Control and Complications Trial, which positively answered the long debate about the relationship between glucose control and diabetes complica- 
tions.

\section{DCCT-UKPDS to 2008}

This era can be recognized as glucocentric doctrine, the lower the better. Perhaps no one study has such an impact as DCCT. The DCCT, UKPDS and the Kumamoto Study were targeted to achieve a near normalization of blood glucose control [3] [6] [7].

In both the DCCT and UKPDS, the rate of complications appeared to follow a positive linear relationship to $\mathrm{HbAlc}$ values. The risk of hypoglycemia was similarly increased with lower $\mathrm{HbAlc}$ values. There was no cutoff $\mathrm{HbAlc}$ value where benefits are maximized and risks minimized [3] [6].

In DCCT the goal of intensive therapy was to achieve glycemic levels in the nondiabetic range $(\mathrm{HbAlc}<6.05 \%)$; the mean $\mathrm{HbAlc}$ actually achieved with intensive therapy was $7.2 \%$ during the study, approximately $2 \%$ lower than that achieved with conventional therapy. The intensive treatment reduced the development of retinopathy by $76 \%$ and slowed its progression by $54 \%$ in primary and secondary cohorts respectively. The incidence of hypoglycemia was three times higher in intensive group [3] Figure 1.

The updated mean HbAlc during the trial and the years of follow-up in the study are the most important predictors of the risk of complications in the conventional treatment group, instead in the intensive treatment group the updated mean $\mathrm{HbAlc}$ is the dominant predictor of the risk of complications. A $10 \%$ lower $\mathrm{HbAlc}$ (e.g., $8 \%$ vs. $7.2 \%$ ) is associated with a $43 \%$ lower risk in the intensive group and a $45 \%$ lower risk in the conventional group for retinopathy progression [8]. This provides a strong affirmation of the glucocentric hypothesis.

The suggestion that lowering HbAlc from $8 \%$ results only in small benefit was strongly refuted by the DCCT researchers [9] [10] [11] [12]. Further the UKPDS with a difference of $7 \%$ vs. $7.9 \%$ in the interventional and conventional arm showed an overall reduction of $25 \%$ in microvascular complications. Again no threshold of glycemia was evident for a substantial change in risk for any of the clinical outcomes studied, each $1 \%$ reduction in HbAlc value decreased microvascular complications by $37 \%$, risk of death related to diabetes by $21 \%$ and vascular event rates were lower at $\mathrm{HbAlc}$ values as low as 5.5\%, showing that the lower the glycemia, the lower the risk of complications [13].

The follow up studies of DCCT in 2005 showed a risk reduction of 42\% (95\% CI 9 - 63) for cardiovascular events and 57\% (95\% CI 12 - 79) for severe clinical events, including non-fatal myocardial infarction, stroke or death from CVD [14]. Similarly 10 year follow up of UKPDS in 2008 reveal risk reduction for diabetes-related mortality (17\%, 95\% CI 4 - 27) and myocardial infarction (15\%, 95\% CI 3 - 26) in addition to persisted relative reduction for any diabetes-related outcome (9\%, 95\% CI 1 - 17) and microvascular complications [15]. The intensive treatment group continued to reap the benefits of earlier good control despite the fact the differences in $\mathrm{HbAlc}$ values is no longer existed. 


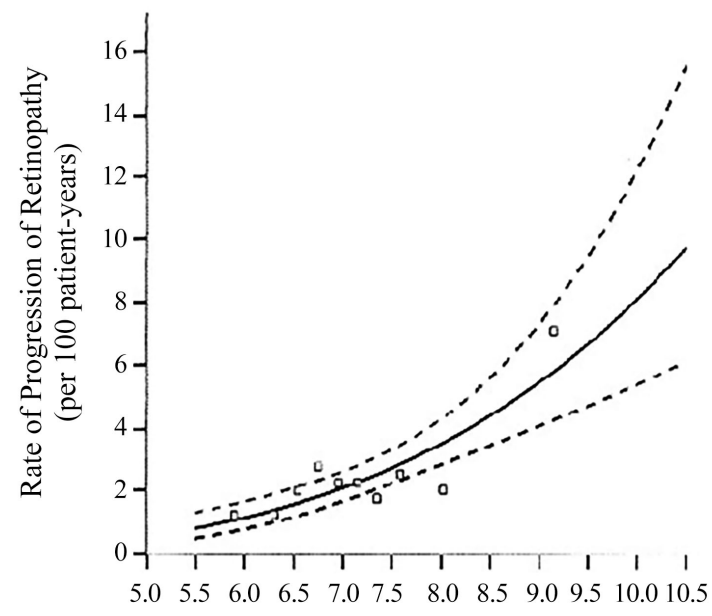

Glycosylated Hemoglobin (\%)

(a)

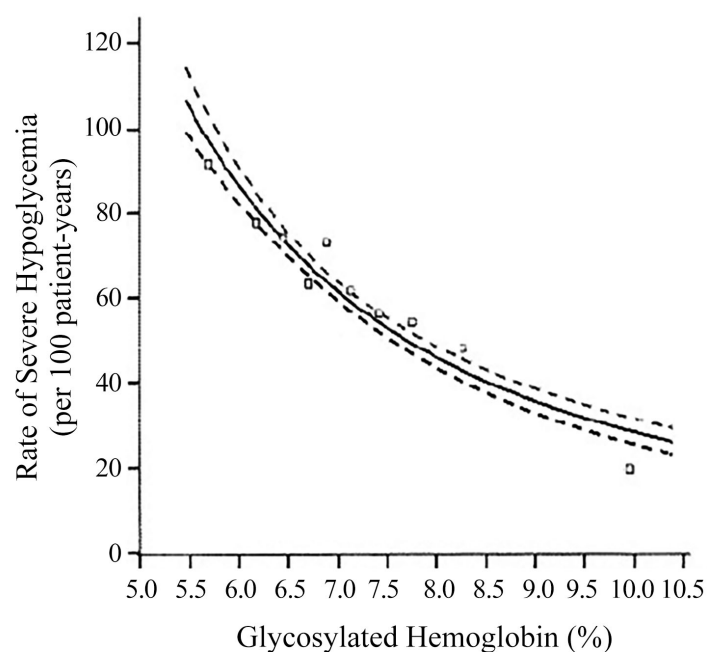

(b)

Figure 1. Risk of Sustained Progression of Retinopathy (Panel a) and Rate of Severe Hypoglycemia (Panel b) in the Patients Receiving Intensive Therapy according to their mean glycosylated hemoglobin values during the trial. In Panel a, the glycosylated hemoglobin values used were the mean of the values obtained every six months. In Panel b, the mean of the monthly values was used. Squares indicate the crude rates within deciles of the mean glycosylated hemoglobin values during the trial; each square corresponds to more than 400 patient-years. The solid lines are regression lines estimated as a function of the log of the mean glycosylated hemoglobin value in Panel a and the log of the glycosylated hemoglobin value in Panel b; the dashed lines are 95 percent confidence intervals. Reproduced from N Engl J Med. 1993 Sep 30; 329 (14): 977-986.

\section{ACCORD, ADVANCE \& VADT}

The population in the DCCT and UKPDS trials were younger and had recent onset of diabetes with neither prior cardiovascular events nor cardiovascular risk factors other than diabetes. However the enthusiasm, the lower the better, or tight glycemic control can prevent cardiovascular events, as proposed by epidemiological data, led to three large, multicenter trials ACCORD, ADVANCE \& VADT. These trials were conducted in older patients with well-established type 2 diabetes mellitus and either multiple risk factors or a previous CVD event. All these three trials did not show improvement in CVD end points [16] [17] [18].

In ACCORD trial the participants in the intensive glycemia group had a median $\mathrm{HbA1C}$ of $6.4 \%$ throughout the trial with $25 \%$ achieving $\mathrm{HbA} 1 \mathrm{c}$ below $6.1 \%$. This was achieved aggressively within four months with concomitant use of insulin and three to four oral agents. This quick decline of HbA1c of almost $2 \%$ from baseline was associated with a 3 -fold increase in severe hypoglycemic events requiring third party or medical assistance. The ACCORD showed increase all cause and CV mortality [16]. In Advance the glycemic goal was pursued less aggressively achieving an $\mathrm{HbA1c}<6.5 \%$ in 3 years, with absolute $\mathrm{HbA} 1 \mathrm{c}$ difference in intensive vs. conventional treatment was $0.8 \%$. The primary outcome was a composite of micro- and macrovascular end-points, improved significantly, however when the different end-points examined separately, it was found that nephropathy (microalbuminuria), but not CVD, was significantly prevented by intensive control [17]. 
The VADT examined poorly controlled type 2 diabetes and able to attain an HbAlc averaged $7.0 \%$ in the intensive control arm vs. $8.5 \%$ in the standard treatment arm. The intensive control did not achieve any CVD advantage in the VADT but there was a non-significant increase in CVD death, consistent with the ACCORD data [18].

Finally the ORIGIN, a trial of 12,537 patients, maintained a target normal fasting plasma glucose levels for more than 6 years, insulin glargine had a neutral effect on cardiovascular outcomes [19].

Era of Individualization-Patient Centered Approach (Figure 2)

The above findings from clinical trials has led to the realization that one size does not fit all and patient's clinical characteristics and psychosocial setting should demand a more tailored approach in establishing a specific glycemic target [21] [22] [23]. Increasing age, duration of diabetes and presence of comorbid conditions have influence in achieving glycemic targets [24]. These may limit life expectancy, increase complexity in the management and may increase burden of treatment.

Age is an important consideration as younger patients, if not well controlled, has greater cumulative exposure to hyperglycemia and subsequent risk for complications. Moreover the ACCORD trial reported a trend toward lower all-cause mortality among participants younger than 65 years at baseline, whereas the ADVANCE trial reported lower rates of combined major macro- and microvascular events in younger participants, however, neither finding was statistically significant. Therefore, a near-normal HbAlc target range seems appropriate for younger patients, who are unlikely to have established CVD [23].

Similar is the case with duration of diabetes, UKPDS recruited newly diagnosed and the long-term follow-up of the UKPDS showed fewer micro- and macrovascular events as a result of previous intensive control. In contrast in the ACCORD and ADVANCE trials and the VADT had type 2 diabetes mellitus for 8.0 to 11.5 years. Thirty two to $40 \%$ of patients in these trials had a history of a CVD event; these participants in the intensive arm of treatment had greater mortality [23].

Severe hypoglycemia occurred approximately 2 to 3 times more oven with intensive therapy in the trials. The ACCORD and ADVANCE trials both reported higher mortality rates in participants with 1 or more episodes of severe hypoglycemia. For this reason, less intensive HbA1c targets are widely accepted as appropriate for patients with recent severe hypoglycemia [21] [23] [24].

\section{ACP 2018 Guideline}

In April 2018 came up with guidance statement suggesting that $\mathrm{HbAlc}$ of 7\% $8 \%$ is appropriate for most of the patients with type 2 diabetes. It consists of four guidance statements [25].

Guidance Statement 1:

Clinicians should personalize goals for glycemic control in patients with type 


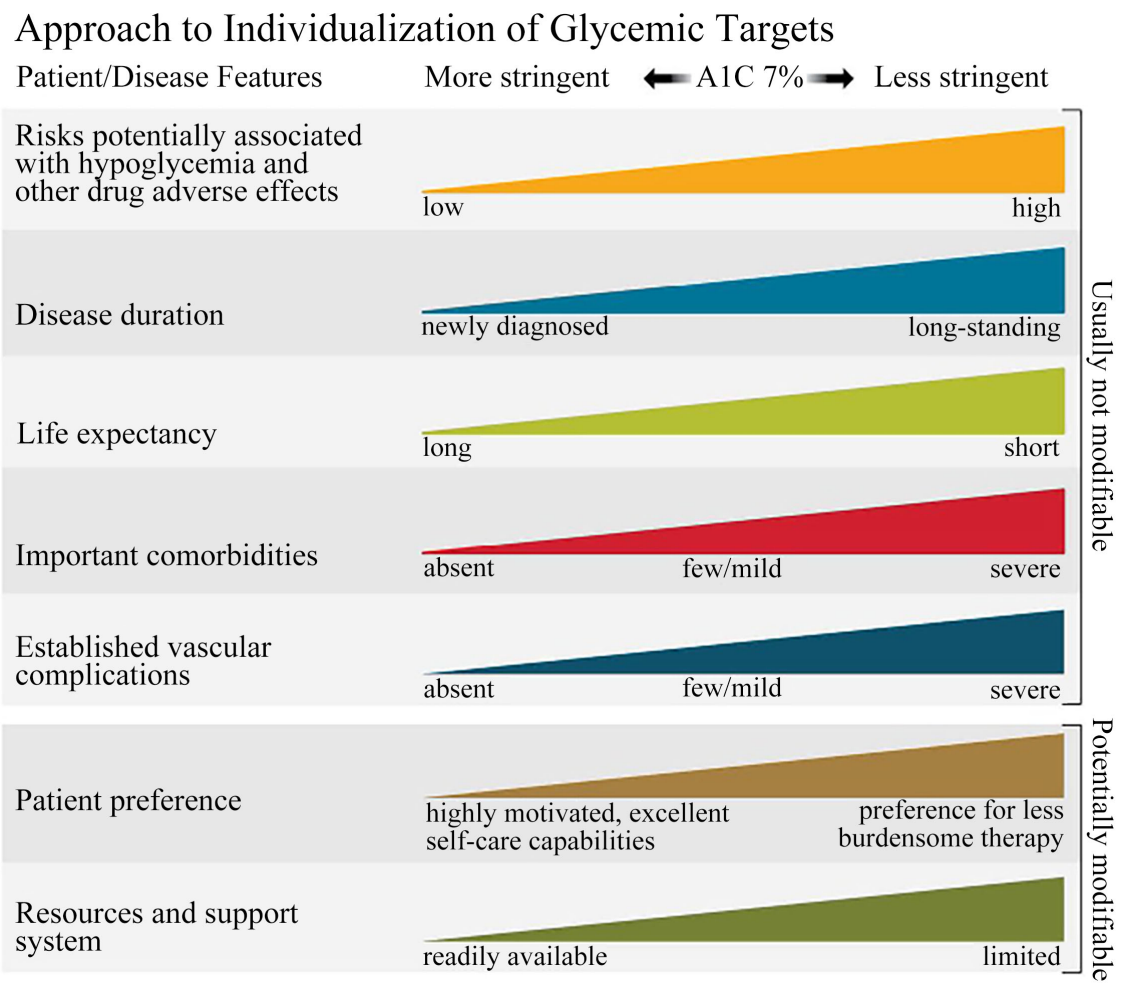

Figure 2. Depicted are patient and disease factors used to determine optimal A1C targets. Characteristics and predicaments toward the left justify more stringent efforts to lower A1C; those toward the right suggest less stringent efforts. A1C $7 \%=53 \mathrm{mmol} / \mathrm{mol}$. Diabetes Care. 2020 Jan; 43 (Suppl 1): S66-S76 [20].

2 diabetes on the basis of a discussion of benefits and harms of pharmacotherapy, patients' preferences, patients' general health and life expectancy, treatment burden, and costs of care.

Guidance Statement 2:

Clinicians should aim to achieve an $\mathrm{HbAlc}$ level between $7 \%$ and $8 \%$ in most patients with type 2 diabetes.

Guidance Statement 3:

Clinicians should consider deintensifying pharmacologic therapy in patients with type 2 diabetes who achieve HbAlc levels less than 6.5\%.

Guidance Statement 4:

Clinicians should treat patients with type 2 diabetes to minimize symptoms related to hyperglycemia and avoid targeting an $\mathrm{HbA1c}$ level in patients with a life expectancy less than 10 years due to advanced age (80 years or older), residence in a nursing home, or chronic conditions (such as dementia, cancer, end-stage kidney disease, or severe chronic obstructive pulmonary disease or congestive heart failure) because the harms outweigh the benefits in this population.

This guidance statement raised considerable controversy. The opponents claims that ACP guidance is based on older studies and ignored the newer studies and therapeutics of the past decade. It also misinterpreted the cardiovascular out- 
come trials and based heavily on ACCORD trial. They fear that by loosening the $\mathrm{HbA1c}$ goals to $7 \%$ to $8 \%$, HbA1c levels realistically might oven exceed $8 \%$. Furthermore a $1 \%$ absolute increase in $\mathrm{HbAlc}$ level translates into a ti7\% increased risk for severe microvascular end points, as per UKPDS data [26] [27] [28].

$\mathrm{ACP}$ believes that an $\mathrm{HbAlc}$ between $7 \%$ and $8 \%$ is where the science shows the best balance of benefits and harms and more intensive HbAlc targets lead to greater healthcare burden and costs, with higher doses of drugs and more hypoglycemic medications, necessitating increased patient and glucose monitoring-and more adverse events.

The common ground where strong agreement exists that care should be individualized. Individualized care includes taking into account the patient's risk for hypoglycemia, weight gain, and other drug-related side effects, along with age, life expectancy, other chronic conditions, functional and cognitive impairments, fall risk, ability to adhere to treatment, and medication burden and cost.

\section{The Advances in Therapeutics}

DCCT, where incidence hypoglycemia was three times higher in the intensive group, was conducted in the pre-Analog era of insulin. Rapid and long acting analogs have made it easier to achieve intensive glycemic targets safely without additional risk of hypoglycemia [29]. Sensor augmented pumps, where pump suspend insulin delivery for 30 minutes at low blood sugar, provides additional safeguard [30]. Automated insulin delivery systems increase and decrease insulin delivery based on sensor-derived glucose level are increasingly been studied and showed that such systems reduce A1C levels and improve time in range of glucose readings.

Similarly in type 2 diabetes, newer agents like GLP-1 receptor agonists and SGLT 2 inhibitors are not only effective antihyperglycemic agents with minimal risk of hypoglycemia but also reduces incidence of major adverse cardiovascular events (MACE), heart failure and diabetic and non-diabetic kidney disease [31] [32] [33].

\section{Moving to Newer Measures of Glycemic Control-The Technology Revolution}

Continuous glucose monitoring (CGM) has emerged as a powerful tool and is transforming the management of type 1 diabetes (T1D) or type 2 diabetes (T2D). In real time, CGM can help patients to take immediate therapeutic action to treat or prevent hypoglycemia and hyperglycemia. Review of last 10 - 14 days data quantifies the time in target range and the time in hypoglycemia and hyperglycemia, and the patterns of hypoglycemia, hyperglycemia, and glucose variability. An A1C value can also be estimated from this data, this is now referred to as Glucose management indicator (GMI) [34]. It tells you the likely approximate A1C level, based on the average glucose level from 14 or more days of CGM readings. 


\section{AGP Report}

Name

MRN
GLUCOSE STATISTICS AND TARGETS

14 days
\% Sensor Time

Average Glucose

Glucose Management Indicator (GMI)

Glucose Variability

Defined as percent coefficient of variation (\%CV); target $\leq 36 \%$
TIME IN RANGES

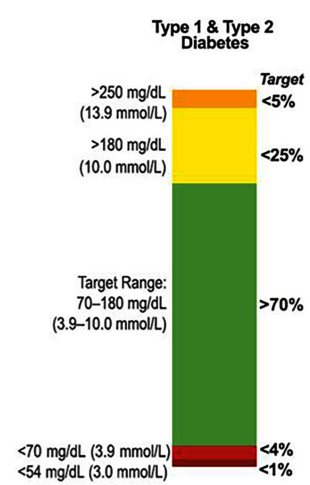

Figure 3. Sample Ambulatory Glucose Profile (AGP) report. Diabetes Care 2020 Jan; 43 (Supplement 1): S66-S76.

In 2020, ADA position statement made recommendations for a standardized, single-page glucose reports and time in range(TIR) $(70-180 \mathrm{mg} / \mathrm{dl})$, time below target $(<70$ and $<54 \mathrm{mg} / \mathrm{dL})$ and time above target $(>180 \mathrm{mg} / \mathrm{dL})$ parameters (Figure 3).

ADA acknowledged that published data suggest a strong correlation between TIR and A1C, with a goal of 70\% TIR aligning with an A1C of; 7\% in two prospective studies. Standardized continuous glucose monitoring (CGM) metrics for clinical care are also published. This was preceded by an international consensus report in 2019 [20] [35].

The initial enthusiasm in the post DCCT and UKPDS era has led to the improvement in glycemic control as reflected by the comparison of National Health and Nutrition surveys (NHANES), conducted between 1999 and 2010, this later seems to be plateaued in subsequent assessments in 2015-2018 surveys [36] [37].

\section{Summary of Glycemic Recommendations for Nonpregnant Adults with Diabetes}

ADA recommended an A1C of $<7 \%$ with additional action suggested for values $>8 \%$ from 1994-2002 and preprandial plasma glucose values of $90-130$ $\mathrm{mg} / \mathrm{dl}$ and average bedtime plasma glucose values of $110-150 \mathrm{mg} / \mathrm{dl}$. The corresponding capillary blood glucose values were reported till 1998. The A1C value was based on referenced nondiabetic A1C range of 4.0\% - 6.0\% using a DCCT-based assay. In 2003 the general recommendation remained A1C 7.0\% with preprandial plasma glucose 90 - $130 \mathrm{mg} / \mathrm{dl}$ and peak postprandial plasma glucose $180 \mathrm{mg} / \mathrm{dl}$ replaced the bedtime glucose. The additional emphasis on individualization of goals with less intensive glycemic goals may be indicated in patients with severe or frequent hypoglycemia. After the ACCORD, in 2009, there was further em- 
phasis on individualization of glycemic goals based on duration of diabetes, age/life expectancy, comorbid conditions, known CVD or advanced microvascular complications, hypoglycemia unawareness, and individual patient considerations. After the follow up studies of DCCT and UKPDS, in 2015, the A1C target of $<7 \%$ was further stressed upon as it is associated with long-term reduction in macrovascular disease in these epidemiological studies. A more stringent goal of $<6.5 \%$ (class $\mathrm{C}$ ) and less stringent target of $<8 \%$ was further emphasized (class B). In year 2021 targets related to CGMS were incorporated as part of recommendation "If using ambulatory glucose profile/glucose management indicator to assess glycemia, a parallel goal is a time in range of $>70 \%$ with time below range $<4 \%$ (B)" [38].

The ACE/AACE guideline emphasized an A1C target of $<6.5 \%$ if can be achieved safely [39]. The current NICE guideline recommends A1C $<6.5 \%$ and $<7 \%$ for individuals not taking and taking medication with potential of hypoglycemia [40]. Furthermore the recommendations of pharmacologic agents are now also individualized based on comorbid conditions, risk of hypoglycemia and weight gain and cost of care.

The pitfalls and limitations of $\mathrm{HbAlC}$, which has served as the main therapeutic marker for last four decades, have now been increasingly recognized. The future perhaps lies in the parameters of ambulatory blood glucose profile, the challenge is how this can be made available and affordable to enormously growing population of people with diabetes.

\section{Author Contributions}

MQM conceptualized and wrote the manuscript.

\section{Acknowledgements}

The technical support was provided by Ms. Farah Khalid in putting the references on the end note.

\section{Conflicts of Interest}

The author declares no conflicts of interest regarding the publication of this paper.

\section{References}

[1] Lynn, L.D. (2009) Historical Note; Frederick Madison Allen, MD. 1879-1964. The Endocrinologist, 19, Article No. 93.

[2] de Leiva-Hidalgo, A. and de Leiva-Pérez, A. (2020) Experiences of First Insulin-Treated Patients (1922-1923). American Journal of Therapeutics, 27, e13-e23. https://doi.org/10.1097/MJT.0000000000001069

[3] Diabetes Control and Complications Trial Research Group (1993) The Effect of Intensive Treatment of Diabetes on the Development and Progression of Long-Term Complications in Insulin-Dependent Diabetes Mellitus. New England Journal of Medicine, 329, 977-986. https://doi.org/10.1056/NEJM199309303291401 
[4] https://www.chemeurope.com/en/encyclopedia/Elliott_P._Joslin.html

[5] Hirsch, I.B., Battelino, T., Peters, A.L., Chamberlain, J.J., Aleppo, G. and Bergenstal, R.M. (2018) Role of Continuous Glucose Monitoring in Diabetes Treatment. American Diabetes Association, Arlington. https://doi.org/10.2337/db20181

[6] UK Prospective Diabetes Study (UKPDS) Group (1998) Intensive Blood-Glucose Control with Sulphonylureas or Insulin Compared with Conventional Treatment and Risk of Complications in Patients with Type 2 Diabetes (UKPDS 33). Lancet, 352, 837-853. https://doi.org/10.1016/S0140-6736(98)07019-6

[7] Ohkubo, Y., Kishikawa, H., Araki, E., Miyata, T., Isami, S., Motoyoshi, S., Kojima, Y., Furuyoshi, N. and Shichiri, M. (1995) Intensive Insulin Therapy Prevents the Progression of Diabetic Microvascular Complications in Japanese Patients with Non-Insulin-Dependent Diabetes Mellitus: A Randomized Prospective 6-Year Study. Diabetes Research and Clinical Practice, 28, 103-117. https://doi.org/10.1016/0168-8227(95)01064-K

[8] The Diabetes Control and Complications Trial Research Group (1995) The Relationship of Glycemic Exposure $\left(\mathrm{HbA}_{1 \mathrm{c}}\right)$ to the Risk of Development and Progression of Retinopathy in the Diabetes Control and Complications Trial. Diabetes, 44, 968-983. https://doi.org/10.2337/diab.44.8.968

[9] Sipperstein, M.D. and Browner, W.S. (1995) The Case for Moderate Rather than Tight Glucose Control in Insulin-Dependent Diabetes mellitus. Clinical Diabetes, 13, 7-9.

[10] Krolewski, A.S., Laffel, L.M.B., Krolewski, M., Quinn, M. and Warram, J.H. (1995) Glycosylated Hemoglobin and the Risk of Microalbuminuria in Patients with Insulin-Dependent Diabetes Mellitus. New England Journal of Medicine, 332, 1251-1255. https://doi.org/10.1056/NEJM199505113321902

[11] Viberti, G. (1995) A Glycemic Threshold for Diabetic Complications? New England Journal of Medicine, 332, 1293-1294. https://doi.org/10.1056/NEJM199505113321909

[12] American Diabetes Association (1996) The Absence of a Glycemic Threshold for the Development of Long-Term Complications: The Perspective of the Diabetes Control and Complications Trial. Diabetes, 45, 1289-1298.

https://doi.org/10.2337/diab.45.10.1289

[13] American Diabetes Association (2002) Implications of the United Kingdom Prospective Diabetes Study. Diabetes Care, 25, s28-s32.

https://doi.org/10.2337/diacare.25.2007.S28

[14] The Diabetes Control and Complications Trial/Epidemiology of Diabetes Interventions and Complications (DCCT/EDIC) Study Research Group (2005) Intensive Diabetes Treatment and Cardiovascular Disease in Patients with Type 1 Diabetes. New England Journal of Medicine, 353, 2643-2653.

https://doi.org/10.1056/NEJMoa052187

[15] Holman, R.R, Paul, S.K., Bethel, M.A., Matthews, D.R. and Neil, H.A. (2008) 10-Year Follow-up of Intensive Glucose Control in Type 2 Diabetes. New England Journal of Medicine, 359, 1577-1589. https://doi.org/10.1056/NEJMoa0806470

[16] Action to Control Cardiovascular Risk in Diabetes Study Group (2008) Effects of Intensive Glucose Lowering in Type 2 Diabetes. New England Journal of Medicine, 358, 2545-2559. https://doi.org/10.1056/NEJMoa0802743

[17] ADVANCE Collaborative Group (2008) Intensive Blood Glucose Control and Vascular Outcomes in Patients with Type 2 Diabetes. New England Journal of Medicine, 358, 2560-2572. https://doi.org/10.1056/NEJMoa0802987 
[18] VADT Study Group (2018) Long-Term Follow-up of Intensive Glycaemic Control on Renal Outcomes in the Veterans Affairs Diabetes Trial. Diabetologia, 61, 295-299. https://doi.org/10.1007/s00125-017-4473-2

[19] ORIGIN Trial Investigators (2012) Basal Insulin and Cardiovascular and Other Outcomes in Dysglycemia. New England Journal of Medicine, 367, 319-328. https://doi.org/10.1056/NEJMoa1203858

[20] American Diabetes Association (2020) 6. Glycemic Targets: Standards of Medical Care in Diabetes-2020. Diabetes Care, 43, S66-S76. https://doi.org/10.2337/dc20-S006

[21] Ismail-Beigi, F., Moghissi, E., Tiktin, M., Hirsch, I.B., Inzucchi, S.E. and Genuth, S. (2011) Individualizing Glycemic Targets in Type 2 Diabetes Mellitus: Implications of Recent Clinical Trials. Annals of Internal Medicine, 154, 554-559. https://doi.org/10.7326/0003-4819-154-8-201104190-00007

[22] Pozzilli, P., Strollo, R. and Bonora, E. (2014) One Size Does Not Fit All Glycemic Targets for Type 2 Diabetes. Journal of Diabetes Investigation, 5, 134-141. https://doi.org/10.1111/jdi.12206

[23] Inzucchi, S.E., Bergenstal, R.M., Buse, J.B., Diamant, M., Ferrannini, E., Nauck, M., Peters, A.L., Tsapas, A., Wender, R. and Matthews, D.R. (2012) Management of Hyperglycemia in Type 2 Diabetes: A Patient-Centered Approach: Position Statement of the American Diabetes Association (ADA) and the European Association for the Study of Diabetes (EASD). Diabetes Spectrum, 25, 154-171.

https://doi.org/10.2337/diaspect.25.3.154

[24] Masood, M.Q., Singh, K., Kondal, D., Ali, M.K., Mawani, M., Devarajan, R., Menon, U., Varthakavi, P., Viswanathan, V., Dharmalingam, M., Bantwal, G., Sahay, R., Khadgawat, R., Desai, A., Prabhakaran, D., Narayan, K.M.V., Tandon, N., on the Behalf of CARRS Trial Group (2021) Factors Affecting Achievement of Glycemic Targets among Type 2 Diabetes Patients in South Asia: Analysis of the CARRS Trial. Diabetes Research and Clinical Practice, 171, Article ID: 108555. https://doi.org/10.1016/j.diabres.2020.108555

[25] Qaseem, A., Wilt, T.J., Kansagara, D., Horwitch, C., Barry, M.J., Forciea, M.A., et al. (2018) Hemoglobin $A_{1 c}$ Targets for Glycemic Control With Pharmacologic Therapy for Nonpregnant Adults with Type 2 Diabetes Mellitus: A Guidance Statement Update From the American College of Physicians. Annals of Internal Medicine, 168, 569-576. https://doi.org/10.7326/M17-0939

[26] Bloomgarden, Z., Einhorn, D., Handelsman, Y., Misra, A., Zonszein, J., Grunberger, G., Jellinger, P.S., Garber, A.J. (2018) American College of Physicians Diabetes Guidelines Attempt to Turn Back the Clock, Conflating Good HbA1c with Hypoglycemia. Journal of Diabetes, 10, 618-620. https://doi.org/10.1111/1753-0407.12668

[27] Draznin, B., Nathan, D.M., Korytkowski, M.T., McDonnell, M.E., Golden, S.H., Schutta, M.H. and Cefalu, W.T. (2018) Guidelines versus Guidelines: What's Best for the Patient? Annals of Internal Medicine, 169, 186-187. https://doi.org/10.7326/M18-0939

[28] Riddle, M.C., Gerstein, H.C., Holman, R.R., Inzucchi, S.E., Zinman, B., Zoungas, S. and Cefalu, W.T. (2018) A1C Targets Should Be Personalized to Maximize Benefits While Limiting Risks. Diabetes Care, 41, 1121-1124. https://doi.org/10.2337/dci18-0018

[29] Hirsch, I.B. (2005) Insulin Analogues. New England Journal of Medicine, 352, 174-183. https://doi.org/10.1056/NEJMra040832

[30] Bergenstal, R.M., Klonoff, D.C., Garg, S.K., Bode, B.W., Meredith, M., Slover, R.H., 
Ahmann, A.J., Welsh, J.B., Lee, S.W. and Kaufman, F.R., for the ASPIRE In-Home Study Group (2013) Threshold-Based Insulin-Pump Interruption for Reduction of Hypoglycemia. New England Journal of Medicine, 369, 224-232. https://doi.org/10.1056/NEJMoa1303576

[31] Marso, S.P., Daniels, G.H., Brown-Frandsen, K., Kristensen, P., Mann, J.F., Nauck, M.A., Nissen, S.E., Pocock, S., Poulter, N.R., Ravn, L.S., Steinberg, W.M., Stockner, M., Zinman, B., Bergenstal, R.M. and Buse, J.B., for the LEADER Steering Committee on behalf of LEADER Trial Investigators (2016) Liraglutide and Cardiovascular Outcomes in Type 2 Diabetes. New England Journal of Medicine, 375, 311-322. https://doi.org/10.1056/NEJMoa1603827

[32] McMurray, J.J.V., Solomon, S.D., Inzucchi, S.E., Køber, L., Kosiborod, M.N., Martinez, F.A, Ponikowski, P., Sabatine, M.S., Anand, I.S., Bělohlávek, J., Böhm, M., Chiang, C.E., Chopra, V.K., de Boer, R.A., Desai, A.S., Diez, M., Drozdz, J., Dukát, A., Ge, J., Howlett, J.G., Katova, T., Kitakaze, M., Ljungman, C.E.A., Merkely, B., Nicolau, J.C., O’Meara, E., Petrie, M.C., Vinh, P.N., Schou, M., Tereshchenko, S., Verma, S., Held, C., DeMets, D.L., Docherty, K.F., Jhund, P.S., Bengtsson, O., Sjöstrand, M. and Langkilde, A.M., for the DAPA-HF Trial Committees and Investigators (2019) Dapagliflozin in Patients with Heart Failure and Reduced Ejection Fraction. New England Journal of Medicine, 381, 1995-2008. https://doi.org/10.1056/NEJMoa1911303

[33] Heerspink, H.J.L., Stefánsson, B.V., Correa-Rotter, R., Chertow, G.M., Greene, T., Hou, F.F., Mann, J.F.E., McMurray, J.J.V., Lindberg, M., Rossing, P., Sjöström, C.D., Toto, R.D., Langkilde, A.M., Wheeler, D.C., for the DAPA-CKD Trial Committees and Investigators (2020) Dapagliflozin in Patients with Chronic Kidney Disease. New England Journal of Medicine, 383, 1436-1446. https://doi.org/10.1056/NEJMoa2024816

[34] Bergenstal, R.M., Beck, R.W., Close, K.L., Grunberger, G., Sacks, D.B., Kowalski, A., Brown, A.S., Heinemann, L., Aleppo, G., Ryan, D.B., Riddlesworth, T.D., Cefalu, W.T., Glucose Management Indicator (GMI) (2018) A New Term for Estimating A1C From Continuous Glucose Monitoring. Diabetes Care, 41, 2275-2280. https://doi.org/10.2337/dc18-1581

[35] Battelino, T., Danne, T., Bergenstal, R.M., Amiel, S.A., Beck, R., Biester, T., Bosi, E., et al. (2019) Clinical Targets for Continuous Glucose Monitoring Data Interpretation: Recommendations from the International Consensus on Time in Range. Diabetes Care, 42, 1593-1603. https://doi.org/10.2337/dci19-0028

[36] Ali, M.K., Bullard, K.M., Saaddine, J.B., Cowie, C.C., Imperatore, G. and Gregg, E.W. (2013) Achievement of Goals in U.S. Diabetes Care, 1999-2010. New England Journal of Medicine, 368, 1613-1624. https://doi.org/10.1056/NEJMsa1213829

[37] Wang, L., Li, X., Wang, Z., Bancks, M.P., Carnethon, M.R., Greenland, P., Feng, Y.Q., Wang, H. and Zhong, V.W. (2021) Trends in Prevalence of Diabetes and Control of Risk Factors in Diabetes among US Adults, 1999-2018. JAMA, 25, Article ID: e219883. https://doi.org/10.1001/jama.2021.9883

[38] American Diabetes Association (2021) 6. Glycemic Targets: Standards of Medical Care in Diabetes-2021. Diabetes Care, 44, S73-S84. https://doi.org/10.2337/dc21-S006

[39] Garber, A.J., Handelsman, Y., Grunberger, G., Einhorn, D., Abrahamson, M.J., Barzilay, J.I., Blonde, L., Bush, M.A., DeFronzo, R.A., Garber, J.R., Garvey, W.T., Hirsch, I.B., Jellinger, P.S., McGill, J.B., Mechanick, J.I., Perreault, L., Rosenblit, P.D., Samson, S. and Umpierrez, G.E. (2020) Consensus Statement by the American Association of Clinical Endocrinologists and American College of Endocrinology On The Comprehensive Type 2 Diabetes Management Algorithm-2020 Executive Summary. 
Endocrine Practice, 26, 107-139. https://doi.org/10.4158/CS-2019-0472

[40] NICE (National Institute for Health and Care Excellence) (2015) NICE Guideline, Type 2 Diabetes in Adults: Management. National Institute for Health and Care Excellence, London. https://www.nice.org.uk/guidance/ng28 